\title{
WASH practices and its association with disease and nutritional status of under five children: Evidence from rural Bangladesh
}

\author{
Mohammad Abdul kuddus ${ }^{1}$, Atiqur Rahman Sunny ${ }^{1,2}$, Mizanur Rahman ${ }^{3}$ \\ ${ }^{1}$ Suchana project, WorldFish, Bangladesh Office, Banani, Dhaka, Bangladesh \\ ${ }^{2}$ Dept. of Genetic Engineering and Biotechnology, Shahjalal University of Science and Technology, Sylhet, Bangladesh \\ ${ }^{3}$ Dept. of Food Engineering and Tea technology, Shahjalal University of Science and Technology, Sylhet, Bangladesh
}

\begin{abstract}
This study aimed to assess knowledge and practice of caregivers and its relationship to the disease and nutritional status of children under five years of age in rural areas of Sylhet, Bangladesh. A total of 110 households having 6 to 59 months aged children was selected by simple random method from ten rural communities of three Upazila of Sylhet during September 2019 to February 2020. Descriptive statistics were used to assess the WASH knowledge \& practice and multivariate chi-square analyses were performed to assess associations among diseases \& nutritional status with WASH following a structured questionnaire. The study found a significant association of WASH with childhood disease and nutritional status, and $65 \%$ of children were found to be in a diseased state and $35 \%$ of children were found to be in a diseasefree state within the last six months. The findings sketched that mother with poor wash knowledge and practice was at greater risk for disease outbreaks, disease frequency and duration. The highest incidence of diarrhea was $17 \%$ in children aged 12 to 23 months. Significant effect of WASH was also found in children nutrition status, that was reflected in the ratio of stunted, underweight and wasted children. Integrated convergent work focusing on the provision of clean water within the household, stop open defecation, promotion of hand washing, behavior change and poverty alleviation is needed to improve the situation. Health, nutrition and livelihood programs should be uninterrupted, and mothers or caregivers should be encouraged to participate in these programs.
\end{abstract}

Key words: WASH, Hygiene, Sanitation, Under-five children, Nutrition status, Bangladesh

\section{Corresponding authors}

Atiqur Rahman Sunny, email: atiksunny@yahoo.com 


\section{INTRODUCTION}

Globally, childhood undernutrition is a serious public health concern. Infants and young children worldwide are affected by the multifaceted crisis of malnutrition, although much attention has been paid to tackling the deficiency in the last few decades (Abdul et al., 2020). About 165 million children are suffering from chronic undernutrition (being stunted) and 52 million are suffering from acute malnutrition (being wasted) (UNICEF et al., 2012). There are a number of underlying causes associated with poor nutritional outcomes in children and growing evidence of adverse effects of poor wash practices on child nutrition well-being (Sunny et al., 2021a). The most common assumption is that the poor wash facilities and practices mediate fecal-bacterial infections that cause diarrhea that exacerbates undernutrition. The World Health Organization (WHO) also estimates that $50 \%$ of undernutrition is associated with infections caused by unsafe water, inadequate sanitation or inadequate hygiene. The causes of malnutrition are multifaceted and interconnected, as illustrated by various conceptual frameworks such as UNICEF's widely used conceptual framework, describing the immediate, underlying, and basic causes of malnutrition (UNICEF, 2013).

In 2018, globally, it was estimated that about $21.9 \%$ of infants under the age of five were stunted and $7.3 \%$ were malnourished, and about two in five stunted children were from South Asia. Bangladesh is among one of the countries in the South Asian region have the highest prevalence of childhood malnutrition. According to the World Health Organization (WHO) standards, Bangladesh has a "very high" underweight and wasting rate. Since the 1990s, undernutrition has gradually declined in Bangladesh, but its prevalence remains high. In 2013, 38.7 percent of children under five years of age were stunted (short for their age), 18 percent were wasted (low weight for height), and 35 percent were underweighted (low weight for age). Later according to the Bangladesh Demographic Health Survey (BDHS) 2017, $22 \%$ of children under the age of five were found low weight, $8 \%$ were wasted and $31 \%$ were of them stunted. Stunting (low height for age) is an indicator of chronic under nutrition. Much evidence suggested that malnutrition was associated with poor sanitation and wash practice (Kuddus et al., 2021). Multiple causes of stunting also include poor feeding habits of infant and young children, frequent infections, poor access to food and health care, poor maternal education, early marriage, early first birth, and the degraded status of girls and women in the family and society. 
A UNICEF report stated that poor washing was responsible for 50\% of maternal and childhood underweight, considering the relationship between diarrhea and malnutrition (UNICEF, 2013). It was also suggested that wash interventions implemented with $99 \%$ coverage can reduce stunting incidence by $2.4 \%$ at 36 months of age (Bhutta et al., 2008). Children living in the environments with improved sanitation and hygienic conditions were taller for their age and less stunted than children living in unhealthy conditions. Diarrhea, environmental enteropathy (EE) and parasitic infections are key mediating pathways connecting poor wash to developmental deficits (Lin et al., 2013). Several studies have linked high incidence of infectious diseases, especially diarrhea to poor wash practices. Poor WASH practices together contribute to about $88 \%$ of deaths from diarrheal diseases globally (GsrusPakowska, 2013). Children living in poor sanitary conditions are more exposed to large amounts of pathogens, especially between the ages of six months and two years, when they begin to crawl on the floor and throw objects into their mouths. Researchers further suggested that environmental entropy could be a significant factor in poor growth and could compromise the effectiveness of nutritional interventions (Sunny et al., 2021b, Sunny et al., 2021c). The relationship between diarrhea and malnutrition is complex, although it is well known that malnourished children suffer frequent episodes of diarrhea, while a child's nutritional status is also affected after the diarrhea episode. A study conducted in the Gaza Strip disclosed that sewerage water accessibility increases the risk of acute diarrhea around the home (Abuzerr et al. 2020). Studies in multiple countries have also shown that $25 \%$ of stunting in children under 24 months of age may be responsible for five or more diarrhea episodes in the first 2 years of life (Cairncross et al., 2010; Bado et al., 2016; Nuhu, 2016). Access to improved sanitation was associated with lower mortality, lower risk of pediatric diarrhea and lower risk of mild or severe stunting. Improved water access was linked with a lower risk of diarrhea and a lower risk of mild or severe stunting (Fink G et al., 2011).

The status of nutrition and hygiene practices varies around the world and miserable in the developing countries like Bangladesh (Kuddus et al., 2020; Sunny et al., 2020a). Bangladesh is also struggling to ensure nutrition security, particularly with child under-nutrition in northeastern region. Around 50\% under fiver year children are stunted, $40 \%$ are under weight and $12 \%$ are wasted in the northeastern division Sylhet that reflected the poor scenario of nutrition and hygiene practices (Sunny et al., 2020b). Poor wash and hygiene practices have a strong relationship with the frequency of waterborne diseases particularly diarrhea in children, and practicing good care can reduce the risk (Talukder, 2017). Though diarrheal deaths and the incidence of diarrhea have been declining among children under the age of five worldwide. It 
is essential to draw worldwide attention to improve and enhance access to safe drinking water, sanitation and hygiene conditions among vulnerable communities like Sylhet to reduce diarrheal morbidity and mortality. The habit of washing hands with soap can ensure significant improvement in a child's nutrition and health (Pickering et al., 2015) Access to water, sanitation and hygiene (WASH) is a prerequisite for human well-being, health and even economic development (Ngure et al., 2014).

Therefore, only a few studies have scouted evidence of interaction among various washing ingredients on children's nutrition outcomes. One study identified the relationship between wash practices and nutritional status among under-five children in Noakhali, Bangladesh. Moreover, the relationship between WASH practices, diarrhea and stunting may affect the development of chronic malnutrition, and to analyze this complex relationship, the study aims to evaluate the association of different wash practices with disease frequency and different indicators of nutritional status in under-five children of northeastern Bangladesh. This two-way path may help to understand whether the habit of washing affects the development of the disease as well as the overall growth of children.

\section{Materials and methods}

\subsection{Study design and population}

This was a cross-sectional and observational study in nature. The study was conducted between September 2019 to February 2020 in ten marginal communities of Sylhet Sadar, Golapganj and Kanaighat Upazila under Sylhet district. A total of 110 households who voluntarily agreed to take part in the study were randomly selected with mother / caregiver and child pairs having 659 months aged children. Cochrane's equation was used to calculate the sample size having a precision level at $0.1,90 \%$ confidence limit and $31 \%$ as probability fraction (as undernutrition rate in Bangladesh is $31 \%$ ) and a design effect of 1.7 . The sample size was measured following the Cochran formula $\mathrm{n}_{0}=\mathrm{Z}^{2}(1-\mathrm{P}) \mathrm{P} / \mathrm{d}^{2}$ (Israel, 1992). Later, $10 \%$ non-response rate was added and minimum sample size became107. Nevertheless, eventually data were collected from 110 households. As the under-five children are mostly dependent, their hygiene and sanitation practices depend on mothers/caregivers' practice. So, they were asked how they maintain and practice basic hygiene and sanitation relating to their child (Vivas et al. 2010; Ghosh et al. 2020). 


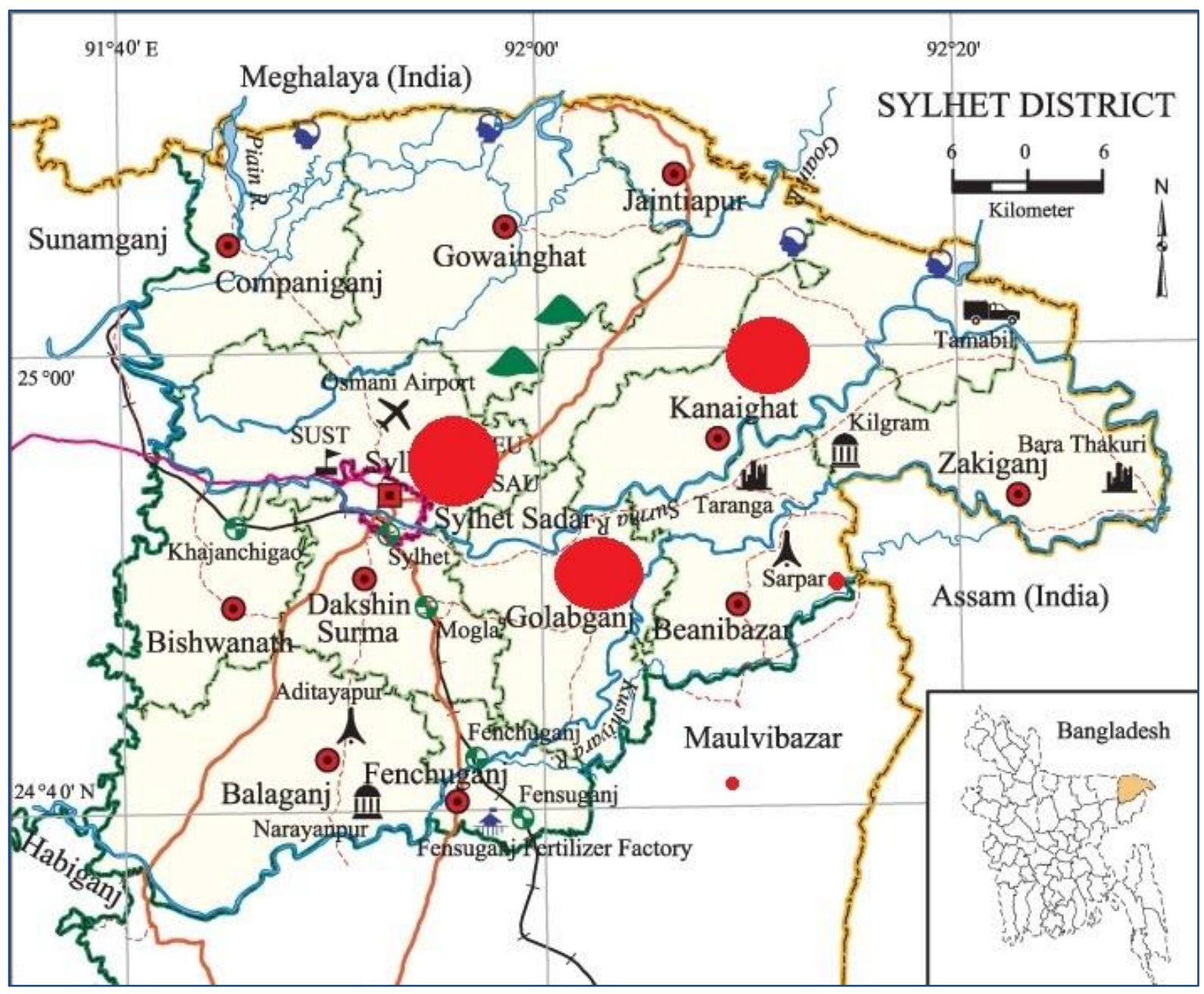

Figure 1: Map of the study areas

\subsection{Data aggregating techniques and consent}

A questionnaire was formed containing both open and closed-ended questions to aggregate relevant information on socioeconomic, anthropometric, knowledge and practice regarding water, sanitation, nutrition, and hygiene. The questionnaire was pre-tested, modified, and adjusted. After pretesting the individual questionnaires which were related to quantitative data, were improved and reformed to ensure content coverage, sequence of the questions, duration of the interview, reliability, and validity of the study

\subsection{Anthropometric Measurement}

The health and nutritional status of the children was assessed by anthropometric measurements. Physical measurements included body weight, height, circumference of arm and head. The anthropometric data were measured following the below procedure.

\subsubsection{Age detection}


The age of the subjects under study was determined and had been confirmed through interrogation and inquiry. The age of the children was gathered from the parents, and they were asked to bring birth certificates or vaccination cards of the children. If parents could not tell the accurate age, then auxiliary forages were carried out. For example, if they could remember a national or religious event when their child was born.

\subsubsection{Body weight measurement}

The body weight was recorded in kilograms by using a standard weighing machine. The children were in bare footed and light cloth during weight measurement to ensure the exact weight. In case of under-two children, if a child couldn't stand the mother took the child in her arms and later the mother's weight was deducted.

\subsubsection{Body height measurement}

The children stood on the platform with barefoot and straight head to measure the height, looking straight ahead using a standard height measurement scale. If a child couldn't stand or was below two years of age, a length measurement board was used for the measurement. The length or height was recorded to the nearest $0.1 \mathrm{~cm}$

\subsubsection{Nutritional status measurement}

The nutritional status was ascertained by Z-score value following WHO classification (WHO, 2006). Sketch of the anthropometric nutritional status is given below

- Underweight or weight for age Z-score (WAZ): The weight for-age Z score (WAZ) could be known as the number of standard deviations of the actual weight from the median weight of the children of his/her age as directed from the standard sample.

Weight for- Age Z Score (WAZ) should be understood as the number of standard deviations of the actual weight of a child from the median weight of the children of his/her age as determined from the standard sample.

- Stunting or height for age Z-score (HAZ): The Height-for- Age Z Score (HAZ) could be known as the number of standard deviations of the actual height from the median height of the children of his/her age as directed from the standard sample.

- Wasting or weight for height Z-score (WHZ): The Weight for- Height Z Score (WHZ) could be known as the number of standard deviations of the actual weight from the median weight of the children of his/her age as directed from the standard sample. 
Table 1: Z-score value for nutritional assessment following WHO classification

\section{Weight for age $\mathrm{Z}$-score}

$-1<\mathrm{WAZ}<0$

$-2<$ WAZ-1

$-3<\mathrm{WAZ}<-2$

WAZ<-3

Height for age $Z$ score

$-1<\mathrm{HAZ}<0$

$-2<$ HAZ $<-1$

$-3<\mathrm{HAZ}<-2$

HAZ<-3

Weight for Height $\mathbf{Z}$ score

$-1<\mathrm{WHZ}<0$

$-2<\mathrm{WHZ}<-1$

$-3<$ WHZ $<-2$

WHZ<-3

\section{Classification}

Normal weight

Mild underweight

Moderate Underweight

Normal weight

Normal stunted

Marginally Stunted

Moderate Stunted

Sever stunted

\subsection{Statistical Analysis:}

The collected data was verified and coded before the computerized data entry. Emergence Nutrition Assessment (ENA) for SMART software was used to assess anthropometric data like $\mathrm{z}$ scores, including weight-for-height, weight-for-age, and height-for-age $\mathrm{z}$ scores. After the $\mathrm{Z}$ score was calculated, the data was transferred to SPSS for further analysis. Descriptive statistical analysis such as mean, range, standard deviations, frequencies, and percentages was performed to determine the WASH knowledge and practice of participants. Chi-square analysis was performed to find out the relationship between disease and nutritional status of under-five children (dependent variables) and WASH knowledge and practices (independent variable). Any variable with $\mathrm{P}$ value $<0.05$ were regarded as a significant factor associated with undernutrition. 


\section{RESUTS}

3.1 Association of WASH knowledge and practices with disease and nutritional status of children

The relationship between diseases status and mother's knowledge and practices was tested using chi-square test of independence and the results shown in the Table 2 below.

Table 2: Association between mother's WASH knowledge \& practice and disease prevalence of children

\begin{tabular}{|c|c|c|c|c|c|c|c|}
\hline \multirow[t]{2}{*}{ Variable } & \multirow[t]{2}{*}{ Scale } & \multicolumn{3}{|c|}{ Disease Prevalence N (\%) } & \multirow[t]{2}{*}{ Total } & \multirow{2}{*}{ Chi- } & \multirow{2}{*}{ p- } \\
\hline & & No disease & Diarrhea & Cold & & & \\
\hline \multirow{2}{*}{ Knowledge } & Good & $25(35)$ & $14(20)$ & $32(45)$ & 71 & \multirow[t]{2}{*}{10.608} & \multirow[t]{2}{*}{$0.005^{*}$} \\
\hline & Poor & $03(10)$ & $14(49)$ & $12(41)$ & 29 & & \\
\hline \multirow{4}{*}{$\begin{array}{l}\text { Practice of } \\
\square \sim \wedge \mathrm{CH}\end{array}$} & Good & $23(35)$ & $16(23)$ & $28(42)$ & 67 & \multirow[t]{2}{*}{10.612} & \multirow[t]{2}{*}{$0.005^{*}$} \\
\hline & Poor & $02(06)$ & $15(46)$ & $16(48)$ & 33 & & \\
\hline & & \multicolumn{3}{|c|}{ Disease Frequency N (\%) } & & & \\
\hline & & No & 2 times & $>2$ times & & & \\
\hline \multirow{2}{*}{ Knowledge } & Good & $25(35)$ & $17(24)$ & $29(41)$ & 71 & \multirow[t]{2}{*}{10.508} & \multirow[t]{2}{*}{$0.005^{*}$} \\
\hline & Poor & $03(10)$ & $04(14)$ & $22(76)$ & 29 & & \\
\hline \multirow{4}{*}{$\begin{array}{l}\text { Practice of } \\
\mathbf{w} \sim \wedge \mathrm{cu}\end{array}$} & Good & $23(35)$ & $15(22)$ & $29(43)$ & 67 & \multirow[t]{2}{*}{10.066} & \multirow[t]{2}{*}{$0.007 *$} \\
\hline & Poor & $02(06)$ & $08(24)$ & $23(70)$ & 33 & & \\
\hline & & \multicolumn{3}{|c|}{ Disease Duration N (\%) } & & & \\
\hline & & No & I day & $>2$ days & & & \\
\hline \multirow{2}{*}{$\begin{array}{l}\text { Knowledge } \\
\text { f } 1 \text { u } A \text { CH }\end{array}$} & Good & $25(35)$ & $07(10)$ & $39(55)$ & 71 & \multirow[t]{2}{*}{6.526} & \multirow[t]{2}{*}{$0.038 *$} \\
\hline & Poor & $03(10)$ & $03(10)$ & $23(79)$ & 29 & & \\
\hline \multirow{2}{*}{ Practice of } & Good & $23(35)$ & $06(08)$ & $38(57)$ & 67 & \multirow[t]{2}{*}{9.908} & \multirow[t]{2}{*}{$0.007^{*}$} \\
\hline & Poor & $02(06)$ & $06(18)$ & $25(76)$ & 33 & & \\
\hline
\end{tabular}

* Level of significant
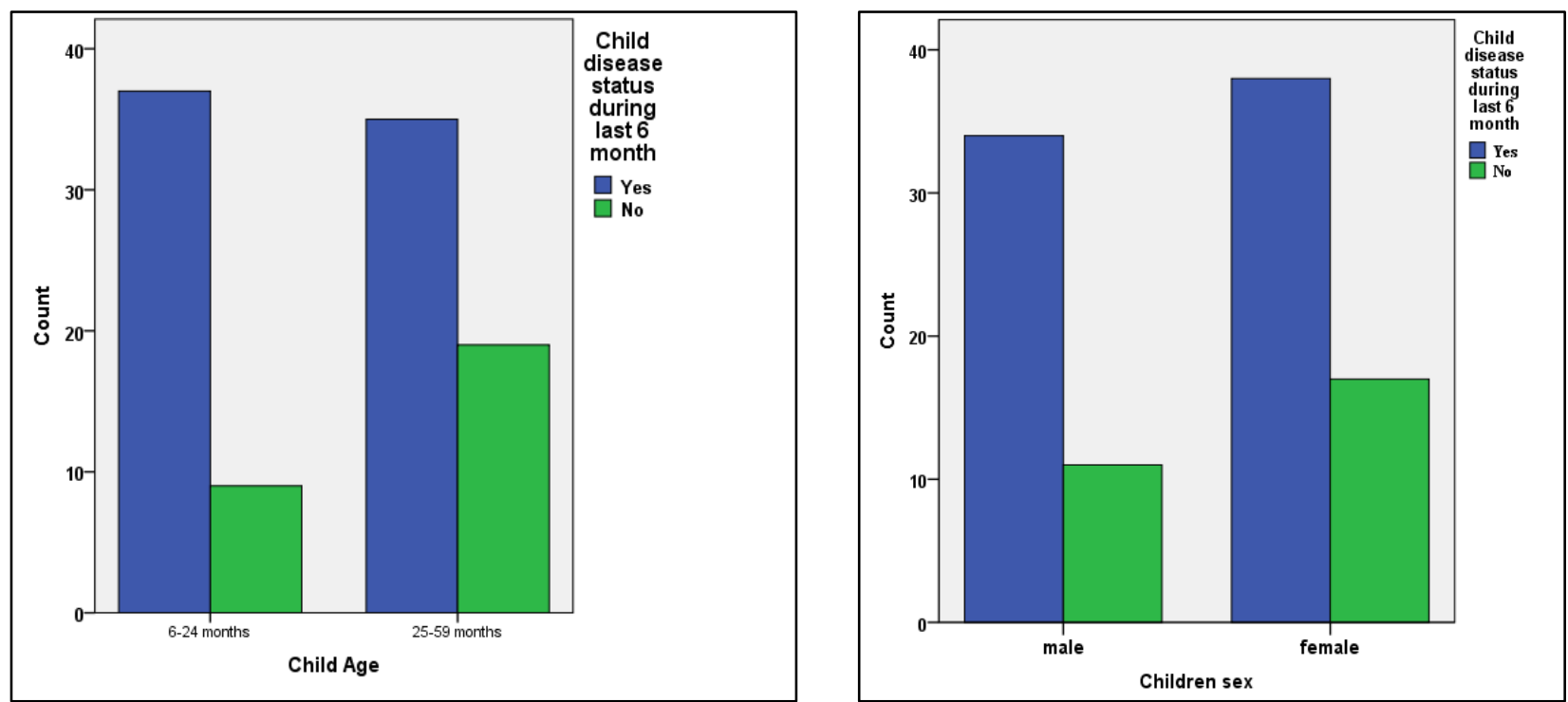

Figure 2: Children disease status during last 6 months 


\subsubsection{Association of mother's WASH knowledge \& practice and Children diseases}

\subsubsection{Disease's prevalence}

A significant relation was found among the mother knowledge \& practice for causation of child disease at $\mathrm{p}>0.01$ level. In case of good knowledge mothers $35 \%$ children recorded diseases free, $65 \%$ diseased children of 71 children. Among the diseased children, $45 \%$ was affected by cold \& fever and $20 \%$ by diarrhea respectively. However, in poor knowledge mother only $10 \%$ found disease free and $90 \%$ found diseased condition of 29 children. Among the diseased children, $49 \%$ was affected by diarrhea and $41 \%$ by cold $\&$ fever respectively.

WASH practice is the main indicator to assess one performance regarding to knowledge, because one can acquire enough knowledge on WASH but not practice in real life that indicates zero performance of knowledge. There is a significant relationship was noted regarding WASH practices and disease prevalence of children at $\mathrm{p}>0.01$ level. And $34 \%$ and $6 \%$ disease free children were documented in good and poor practice respectively. Among diseased children $23 \% \& 42 \%$ were affected by diarrhea and cold fever in good practice and $46 \%$ \& $48 \%$ by diarrhea and cold fever in poor practice respectively. There is relationship was found among child disease status in respective to child age $\&$ sex. And result revealed that younger children were more vulnerable to older and female was more sensitive compare to male for disease during last 6 months of the study period (Figure -2).

\subsubsection{Diseases frequency}

Disease's frequency is an important factor to find out the disease's prevalence of children. Last six months tenure was considered for disease frequency or number of episodes in terms of mother's WASH knowledge \& practices. A significant relationship was found between good and poor WASH knowledge \& practice of mother on their children disease frequency or number of episodes of disease at p $>0.01$ level. Regarding good WASH knowledge only $24 \%$ children were faced two times in morbidity condition where as $42 \%$ children faced that situation in poor WASH knowledge. Considering WASH practice of mothers' significant difference also recorded at $\mathrm{p}>0.01$ level between good and poor practice. In poor WASH practices mother's, $96 \%$ children found two \& more times vulnerable to disease whereas only $65 \%$ children found in good WASH practice. 


\subsubsection{Diseases duration}

Duration of diseases also considered an important and crucial matter for diseases prevalence of children. In terms of disease duration, a distinct and significant relationship was found between good \& poor level WASH knowledge \& practices mothers at p $>0.05 \& \mathrm{p}>0.01$ level respectively. In case good knowledge \& practice diseases duration was recorded one day in $10 \%$ children and more than one day in $8 \% \& 18 \%$ children respectively. However poor knowledge \& practice the duration was recorded one day in $55 \%$ \& $57 \%$ children and $79 \%$ \& $76 \%$ children respectively.

\subsection{Association of mother's WASH knowledge \& practice and nutritional status of Children}

The relationship of nutritional status and mother's knowledge and practices was tested using chi-square test of independence and the results shown in the Table 4.10 below.

Table 2: Association of mother's WASH knowledge \& practice and nutritional status of children

\begin{tabular}{|c|c|c|c|c|c|c|c|}
\hline \multirow[t]{2}{*}{ Variable } & \multirow[t]{2}{*}{ Scale } & \multicolumn{3}{|c|}{ Height age $\mathrm{Z}$ (HAZ) Score $\mathrm{N}(\%)$} & \multirow{2}{*}{ Total N } & \multirow{2}{*}{ Chi- } & \multirow{2}{*}{ p- } \\
\hline & & Stunting & Normal & Over & & & \\
\hline \multirow{2}{*}{ Knowledge } & Good & $31(43)$ & $37(52)$ & $03(05)$ & $71(100)$ & \multirow[t]{2}{*}{7.251} & \multirow[t]{2}{*}{$0.027 *$} \\
\hline & Poor & $21(73)$ & $08(27)$ & $00(00)$ & $29(100)$ & & \\
\hline \multirow{2}{*}{$\begin{array}{l}\text { Practice of } \\
\square \sim \wedge \mathrm{CH}\end{array}$} & Good & $28(42)$ & $36(54)$ & $03(04)$ & $67(100)$ & \multirow[t]{2}{*}{8.987} & \multirow[t]{2}{*}{$0.011^{*}$} \\
\hline & Poor & $24(73)$ & $09(27)$ & $00(00)$ & $33(100)$ & & \\
\hline & \multicolumn{3}{|c|}{ Weight age $Z$ (WAZ) Score N (\%) } & \multirow[t]{2}{*}{ Total $\mathrm{N}$} & & \\
\hline & & Under & Normal & Over & & & \\
\hline \multirow{2}{*}{ 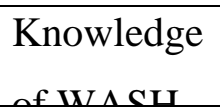 } & Good & $30(42)$ & $32(45)$ & $09(13)$ & $71(100)$ & \multirow[t]{2}{*}{16.504} & \multirow[t]{2}{*}{$0.000 *$} \\
\hline & Poor & $25(86)$ & $04(14)$ & $00(00)$ & $29(100)$ & & \\
\hline \multirow{2}{*}{$\begin{array}{l}\text { Practice of } \\
\Delta \sim \wedge \mathrm{CH}\end{array}$} & Good & $27(40)$ & $33(49)$ & $07(11)$ & $67(100)$ & \multirow[t]{2}{*}{18.358} & \multirow[t]{2}{*}{$0.000 *$} \\
\hline & Poor & $28(85)$ & $03(09)$ & $02(06)$ & $33(100)$ & & \\
\hline & & \multicolumn{3}{|c|}{ Weight height $\mathrm{Z}$ (WHZ) Score $\mathbf{N}$} & \multirow[t]{2}{*}{ Total $\mathrm{N}$} & & \\
\hline & & Wasting & Normal & Over & & & \\
\hline \multirow{2}{*}{$\begin{array}{l}\text { Knowledge } \\
\text { of } \ \mathbf{x} \sim \mathrm{CU}\end{array}$} & Good & $19(27)$ & $45(63)$ & $07(10)$ & $71(100)$ & \multirow[t]{2}{*}{6.054} & \multirow[t]{2}{*}{$0.048 *$} \\
\hline & Poor & $15(52)$ & $13(45)$ & $01(3)$ & & & \\
\hline \multirow{2}{*}{ Practice of } & Good & $17(25)$ & $42(63)$ & $08(12)$ & $67(100)$ & \multirow[t]{2}{*}{9.153} & \multirow[t]{2}{*}{$0.010^{*}$} \\
\hline & Poor & $17(52)$ & $16(48)$ & $00(00)$ & $33(100)$ & & \\
\hline
\end{tabular}

* Level of significant

\subsubsection{Association between mother's WASH knowledge \& practice and Stunting (height-} for-age) of Children

The stunting status of children and WASH knowledge \& practices of mother were found statistically significant. From the height age Z score $43 \%$ stunted, 52\% normal and 5\% over 
nutrition children was recorded in good WASH knowledge respectively which is statistically significant at $\mathrm{p}<0.05$ level. In poor WASH knowledge $73 \%$ stunted, $27 \%$ normal children found which is also significant at $\mathrm{p}<0.05$ level. But no over nutrition was found in poor WASH knowledge. However, the stunting prevalence is significantly high $73 \%$ among the children whose mothers WASH practice was poor; this is almost double compare to good practice.

\subsubsection{Association between mother's WASH knowledge \& practice and Underweight (weight-for-age) of children}

The prevalence of underweight defined by WAZ of $<-2$ to -3 SD. And $42 \%$ and $86 \%$ was noted in case of good and poor knowledge of mother about WASH respectively which statistically significant at $\mathrm{p}<0.00$ level. Besides that WASH practice of mothers effect found on underweight prevalence of children at $\mathrm{p}<0.00$ level significant. The result also showed $40 \%$ and $85 \%$ underweight children which mothers WASH practice level was good and poor respectively.

\subsubsection{Association between mother's WASH knowledge \& practice and wasting (weight- for-height) of Children}

The wasting distribution of the children was also significant regarding mother's knowledge and practice level of WASH. About one third (27\%) children in good knowledge and almost double $(52 \%)$ children found in poor knowledge which is statistically significant at $\mathrm{p}>0.05$ level. On other hand regarding mother WASH practice $25 \%$ children was wasted in good and $52 \%$ recorded in poor WASH practices of mother respectively which also significant at $\mathrm{p}>0.05$ level.

\section{DISCUSSION}

Association between Mother's WASH knowledge \& practices with disease \& nutrition status of children

\subsection{Association between WASH knowledge \& practices and diseases prevalence of children}

\subsubsection{Disease status}

From the result $65 \%$ children found diseased condition \& $35 \%$ diseases free condition during last six months study period. The result also shows not distinct difference in sex although girls more resist from diseases than boys and found 10 boys \& 15 girls with no disease condition but in case of diseased condition regarding to frequency $\&$ duration of diseases, we can see that girls are more sensitive to diseases than boys. The highest diarrhea prevalence (17\%) was found in children aged 12 to 23 months. Prevalence tended to decrease as child's age increased, and the difference in the prevalence was significant between children aged 12 to 23 months and 
older. Diarrhea prevalence was not significantly different between sexes (Agustina et al., 2013). From another study respondents reported hand washing prevent diarrheal diseases while diarrhea was the most identified disease which result from not washing hands, followed by cholera and typhoid (Godfrey T., 2017)

In case of good knowledge mothers found $35 \%$ disease free children \& $65 \%$ diseased children among 71 children, whose $45 \%$ with cold \& fever and only $20 \%$ with diarrhea and but in case of poor knowledge mother result shows only $10 \%$ disease free but $90 \%$ are diseased children among 29 children whose $49 \%$ with diarrhea and $41 \%$ with cold \& fever. Practice is the main indicator to assess one performance than knowledge, because anybody has knowledge in any subject but he/she is not using in his/her practical life. Findings proven that only knowledge is not enough to prevent us from disease, it requires knowledge in practical level. Moreover, that poor practice mothers' children were more suffered in diarrheal diseases than good one.

\subsubsection{Diseases frequency}

In terms of association between WASH hygiene knowledge \& practices found significant difference between good and poor WASH knowledge \& practice mother on their children disease frequency or number of episodes of disease. Children are vulnerable to more disease frequency whose mother found poor knowledge as well as practices of WASH than good knowledge \& practices. Poor WASH practices mothers' children were found more susceptible to more than two times disease episode than good WASH practices mother. Beyond those diarrheal diseases are more recorded in case of poor WASH practices mother than good practices mother. From the (Agustina et al. 2017) study indicates that the risk of having diarrhea is increased in children aged $<2$ years whose mother had poor food-hygiene practices. Children who lived in houses with less dirty sewage had a lower risk of diarrhea. Similarly, environmental enteropathy which is mainly a result of regular ingestion of fecal bacteria due to poor sanitation and hygiene conditions has been reported in under-five children (Humphrey, 2009, Ngure et al., 2014). Proper hand washing with soap (HWWS) which focuses on hygiene promotion is more effective in reduction of diarrhoeal episodes among children and reduces the risk of disease transmission to $47 \%$ (Curtis V, 2003).

\subsubsection{Disease duration}

Association between diseases duration and WASH knowledge \& practices found distinct and significant difference between good \& poor level WASH knowledge \& practices mothers in relation of children disease duration. In case of good WASH knowledge \& practices of mothers children disease duration found more and lower in good WASH practices. A number of studies 
have associated the high prevalence of infectious diseases particularly diarrhea with poor WASH practices (Cairncross et al., 2010; Bado et al., 2016; Nuhu, 2016).

\subsection{Association between WASH knowledge \& practices and nutrition status of children}

\subsubsection{Association between mother's WASH knowledge \& practice and Stunting (height- for-age) of Children}

The stunting status of children has found positive association with mother knowledge \& practices. The more stunted children were recorded who practiced poor WASH with poor knowledge in WASH compare to good knowledge \& practices of WASH. The findings not indicates that children stunting not only depends on WASH practices but also depends on different factors of nutrition sensitive as well as nutrition specific factors. But it's true that WASH factors acts as a catalyzing factor for child nutritional status of under 5 children. A study in Peru found a positive association between improved water sources and HAZ, an effect that was greater when the intervention was combined with improved sanitation facilities (Checkley W. et al., 2004). Rah J et al (2015) conducted a cross-sectional study in India and reported that optimal hand washing practices decreased stunting of risk. The Lancet Maternal and Child Undernutrition Series recently estimated that sanitation and hygiene interventions implemented with $99 \%$ coverage would reduce diarrhea incidence by $30 \%$, which would in turn decrease the prevalence of stunting by only $2.4 \%$. It was also reported from an observational study in rural Bangladesh that children living in the environments with improved sanitation and hygiene conditions were taller for their age and less stunted than those living in unsanitary and unhygienic conditions (Lin et al., 2013).

\subsubsection{Association between mother's WASH knowledge \& practice and undernutrition (weight-for-age) of Children}

Result shows a positive association between mother's WASH knowledge \& practice and undernutrition (weight-for-age) of Children. And the prevalence of underweight has shown distinctly lower in case of good knowledge \& practices mother about WASH whereas higher recorded in poor WASH practices. Weight of children depends on nutrient absorption capacity of the children; usually the absorption capacity becomes low due to prevalence of several times $\&$ long duration of diarrheal diseases. In that case same trends may show from the result. A report from UNICEF stated that poor WASH accounts as much as 50\% of maternal and childhood underweight taking into account the relationship between diarrhea diseases and under nutrition (UNICEF, 2013). 


\subsubsection{Association between mother's WASH knowledge \& practice and Wasting (weight- for-height) of Children}

The nutritional status especially wasting of under-five years children depend much on improved WASH practices such as hygiene conditions of the household members and their surroundings, proper disposal of waste as well as availability of adequate and safe water in the household among other things. Poor WASH practices may affect the wasting status of children and may also affect their growth performance. In case of Wasting and WASH practices have found a significant relationship with mother's knowledge and practice level of WASH. The results are showing that good WASH practices children are nutritionally sound compare to poor WASH practices one. Not only that diarrheal disease prevalence is more recoded in case poor WASH practices than good WASH practices mother. This result indicates that mother knowledge \& practices on WASH has an important factor role on wasting status of children. Because of frequently diarrheal disease may keep barrier for proper nutrition intake as well as proper growth of under 5 children. Good WASH practices say hand washing with soap and 15minute reduction in water collection time were confirmed to improve child nutritional status significantly (Curtis and Cairncross, 2003; Pickering et al., 2015). A study determining the factors associated with childhood malnutrition in 36 low-and middle-income countries suggested that the use of pit latrines and flush toilets had significantly positive effect on the weight-for-height z-score (WHZ) (Smith, Ruel, \& Ndiaye, 2005).

\section{CONCLUSION}

According to different study and observation, the child mortality considerably depends on the water, sanitation and hygiene practice of the mothers of under-five children. Thus the study designed to assess the knowledge \& practices on Water, Sanitation and Hygiene of mothers having under-five children and its relation to child diseases and nutrition

From the study we can see that WASH has significant effect on children disease and nutrition status and found $65 \%$ children diseased condition \& $35 \%$ children no diseases condition during the last six months of study period. The result also shows not distinct difference in sex although girls more resist from diseases than boys and found 10 boys \& 15 girls with no disease condition but in case of diseased condition regarding to frequency \& duration of diseases, we can see that girls are more sensitive to diseases than boys. The findings of the study also proven that poor WASH knowledge \& practices mothers' children are more vulnerable to diseases prevalence, diseases frequency and duration. And the most children found in diarrheal diseases with almost double frequency and duration in case of poor WASH practices mother. And the 
highest diarrhea prevalence $17 \%$ was found in child age 12 to 23 months. Findings proven that only knowledge is not enough to prevent us from disease, it requires dedication to perform in practice level. As of the study we also found WASH effect in children nutrition status, although nutrition status not only depends on WASH but has an influential effect on children nutrition status. In case of poor knowledge \& practices of WASH we found $73 \%$ stunting, $85 \%$ underweight \& $52 \%$ wasting whereas $43 \%$ stunted, $27 \%$ underweight \& $42 \%$ wasted children found in good knowledge and practices of WASH mother's children.

In conclusion, it may say that household sanitation and the mother's/caregiver's reported personal hygiene practices are strong predictors of child disease $\&$ nutritional status in rural community of Bangladesh. This reinforces the growing evidence of the effects of WASH practices on child linear growth. Large-scale randomized effectiveness trials of toilet provision (and use) and reported hand washing at critical times, which include environmental enteropathy and child growth as outcomes, are warranted to go beyond association in order to estimate causality. However, this suggests the need for different programmatic responses by governments and development partners. Optimizing nutrition outcomes for young children now requires a framework that is broader than nutrition-specific interventions alone. In case of vulnerable children and mothers of Bangladesh need to benefit from additional, well-targeted nutrition-sensitive interventions, especially leading up to and during the first 1000 days. Policies and programming aiming to address child nutrition should encompass WASH interventions, thus shifting the emphasis from nutrition-specific to nutrition-sensitive programming. Based on findings it may be recommended that, Government and nongovernment organizations should take initiative to educate mothers/caregivers on appropriate WASH practices for addressing improve child's growth in order to reduce child disease and promote children's nutritional status.

\section{REFERENCES}

Abdul, K.M., Hamid, S.M.A. and Mohsin, S.M., 2020. Study on Knowledge\& Practice of WASH among Under 5 Children's Mother in Rural Community of Bangladesh. International Journal of Rural Development, Environment and Health Research (IJREH), 4 (6), pp 232-241, doi:10.22161/ijreh.4.6.3

Agustina, R., Sari, T.P., Satroamidjojo, S., Bovee-Oudenhoven, I.M., Feskens, E.J. and Kok, F.J. (2013). Association of food-hygiene practices and diarrhea prevalence among Indonesian young children from low socioeconomic urban areas. BMC public health, 13(1), pp.1-12. 
Aigbiremolen A. O, A. C et al. (2015) Knowledge and practice of hand washing among caregivers of under-five Children in a Rural Nigerian Community.

Amponsah SK, Apenkwa J, Ojo L, Solomon KA, Akwasi E, et al. (2018) Assessing the Relationship between Dietary Intake, Hygienic Practices and Protein Energy Malnutrition among Children under Five at Ahafo Ano North District. J Clin Nutr Diet Vol.4 No.1:4

Anna Bowen, H. M., Jianming Ou., Ward Billhimer., Timothy Long., Eric Mintz., Robert M. Hoekstra., Stephen Luby., (2007). A cluster-randomized controlled trial evaluating the effect of a hand washing-promotion program in chinese primary schools.

Bado AR, Susuman AS, Nebie EI. 2016. Trends and risk factors for childhood diarrhea in subSaharan countries (1990-2013): assessing the neighborhood inequalities.Global health action 9 .

Bain R, Cronk R, Hossain R, Bonjour S, Onda K, Wright J et al. (2014). Global assessment of exposure to faecal contamination through drinking water based on a systematic review. Trop Med Int Health. 19(8):917-27.

Bangladesh Bureau of Statistics (BBS), 2007

Bowen A, Agboatwalla M, Luby S, et al. Association between intensive handwashing promotion and child development in Karachi, Pakistan: a cluster randomized controlled trial. Arch Pediatr Adolesc Med. 2012; 166:1037-1044.

Brown J, Cairncross S, Ensink JH. 2013. Water, sanitation, hygiene and enteric infections in children. Archives of disease in childhood, archdischild-2011-301528.

Brown, J., Cairncross, S., \& Ensink, J. H. 2013. Water, sanitation, hygiene and enteric infections in children. Archives of Disease in Childhood, 98(8), 629-634. https://doi.org/10.1136/archdischild-2011-301528

Cairncross S, Hunt C, Boisson S, Bostoen K, Curtis V, Fung IC, Schmidt WP. 2010. Water, sanitation and hygiene for the prevention of diarrhoea. International journal of Epidemiology 39, i 193-i205. 
Casanovas Mdel, C., Lutter, C. K., Mangasaryan, N., Mwadime, R., Hajeebhoy, N., Aguilar, A. M., Onyango, A. W. 2013. Multi-sectorial interventions for healthy growth. Maternal \& Child Nutrition, 9(Suppl 2), 46-57. https://doi.org/10.1111/mcn. 12082

Checkley W, Gilman R, Black R, et al. Effect of water and sanitation on childhood health in a poor Peruvian peri-urban community. Lancet. 2004; 363: 112-118.

Checkley W, et al. Multi-country analysis of the effects of diarrhoea on childhood stunting. Int J Epidemiol 2008;37:816-30.

Curtis V, Cairncross S. 2003. Effect of washing hands with soap on diarrhoea risk in the community: a systematic review. The Lancet infectious diseases 3, 275-281.

Datta SS, Singh Z, Boratne AV, Senthilvel V, Bazroy J and Dimri D. Knowledge and practice of handwashing among mothers of under five children in rural coastal South India: 2011. Int. J. Med. Public health [www.ijmedph.org] Vol 1 | Issue 1

Fenn B, Bulti AT, Nduna T, Duffield A, Watson F. 2012. An evaluation of an operations research project to reduce childhood stunting in a food-insecure area in Ethiopia. Public health nutrition $15,1746-1754$.

Fischer Walker C, Perin J, Aryee M, et al. Diarrhea incidence in low- and middleincome countries in 1990 and 2010: a systematic review. BMC Public Health. 2012; 12: 220.

Freeman MC, Stocks ME, Cumming O, Jeandron A, Higgins JP, Wolf H et al. (2014). Hygiene and health: systematic review of handwashing practices worldwide and update of health effects. Trop Med Int Health. 19(8):906-16.

Gascon J, Vargas M, Schellenberg D, Urassa H, Casals C, Kahigwa E, Aponte J, Mshinda H, Vila J. 2000. Diarrhea in children under 5 years of age from Ifakara, Tanzania: a casecontrol study. Journal of clinical microbiology 38, 4459-4462.

Gautam OPWPS, Sandy Cairncross, Sue Cavill, Valerie Curtis. 2017. Trial of a Novel Intervention to Improve Multiple Food Hygiene Behaviors in Nepal. American Journal of Tropical Medicine and Hygiene 96(6), 2017, pp. 1415-1426.

George C, Oldja L, Biswas S, et al. Fecal markers of environmental enteropathy are associated with animal exposure and caregiver hygiene in Bangladesh. Am J Trop Med Hyg. 2015; 93: 269-275. 
Ghosh, S., Kabir, M., Islam, M., Bin Shadat, Z., Ishat, F.S., Hasan, R., Hossain, I., Alam, S.S. and Halima, O., 2021. Association between water, sanitation, and hygiene practices (WASH) and anthropometric nutritional status among selected under-five children in rural Noakhali, Bangladesh: a cross-sectional analysis. Journal of Water, Sanitation and Hygiene for Development, 11(1), pp.141-151.

Godfrey T. Knowledge, attitude and practice on hand washing among children in households in bukoto i parish nakawa division, kampala disrict, Uganda.2107, Makerere university school of public health.

Gunther Fink, Isabel Gu"nther and Kenneth Hill. The effect of water and sanitation on child health: evidence from the demographic and health surveys 1986-200; International Journal of Epidemiology 2011;40:1196-1204

Humphrey JH. 2009. Child undernutrition, tropical enteropathy, toilets, and handwashing. The Lancet, 374, 1032-1035.

Korpe P, Petri W. Environmental enteropathy: critical implications of a poorly understood condition. Trends Mol Med. 2012; 18:328-336.

Kuberan A, Singh A K, Kasav J B, Prasad S, Surapaneni K S, Upadhyay V, and Joshi A. Water and sanitation hygiene knowledge, attitude, and practices among household members living in rural setting of India: Journal of Natural Science, Biology and Medicine. 6(Suppl 1): S69-S74.

Kuddus, M. A., Datta, G. C., Miah, M.A., Sarker, A.K., Hamid, S.M.A., Sunny, A.R. 2020. Performance Study of selected Orange Fleshed Sweet Potato Varieties in North Eastern Bangladesh. nternational Journal of Environment, Agriculture and Biotechnology, 5(3): 673-682,

Kuddus, M.A., Alam, M.J., Datta, G.C., Miah, M.A., Sarker, A.K. and Sunny, M.A.R. 2021. Climate resilience technology for year round vegetable production in northeastern Bangladesh. Int. J. Agril. Res. Innov. Tech. 11(1): 29-36. https://doi.org/10.3329/ijarit.v11i1.54464

Kumiko Takanashi, Yuko Chonan1, Dao To Quyen, Nguyen Cong Khan, Krishna C. Poudel, and Masamine Jimba. Survey of Food-hygiene Practices at Home and Childhood Diarrhoea in Hanoi, Viet Nam. J health popul nutr 2009 Oct.; 27(5):602-611 
Lin A, Arnold BF, Afreen S, Goto R, Huda TMN, Haque R, Raqib R, Unicomb L, Ahmed T, Colford JM. 2013. Household environmental conditions are associated with enteropathy and impaired growth in rural Bangladesh. The American journal of tropical medicine and hygiene $89,130-137$.

Lin, A., Arnold, B. F., Afreen, S., Goto, R., Huda, T. M. N., Haque, R., Raqib, R., Unicomb, I., Ahmed, T., Colford, J. M. \& Luby, S. P. 2013. Household environmental conditions are associated with enteropathy and impaired growth in rural Bangladesh. The American Journal of Tropical Medicine and Hygiene.

Luby S, Agboatwalla M, Painter J, et al. Combining drinking water treatment and hand washing for diarrhoea prevention, a cluster randomised controlled trial. Trop Med Int Heal. 2006; 11:479-489

Murray C.J., Vos T., Lozano R., Naghavi M., Flaxman A.D., Michaud C. et al. (2013) Disability-adjusted life years (DALYs) for 291 diseases and injuries in 21 regions, 19902010: a systematic analysis for the Global Burden of Disease Study 2010. The Lancet 380, 2197-2223.

Ngure F, Humphrey J, Mbuya M, et al. Formative research on hygiene behaviors and geophagy among infants and young children and implications of exposure to fecal bacteria. Am $\mathbf{J}$ Trop Med Hyg. 2013; 89:709-716.

Ngure FM, Reid BM, Humphrey JH, Mbuya MN, Pelto G, Stoltzfus RJ. 2014. Water, sanitation, and hygiene (WASH), environmental enteropathy, nutrition, and early child development: making the links. Annals of the New York Academy of Sciences 1308, 118128.

Nuhu S, Mpambije CJ. 2016. Water and Sanitation Services in Informal Urban Settlements and their Implications to Peoples Health in Tandale, Dar es Salaam Tanzania. International Journal 64. Operational Experience from Bangladesh. South Asia Hygiene Practitioners' Workshop.

Park K. Park's Textbook of Preventive and Social Medicine. 22 ed. Jabalpur, India: M/s Banarsidas Bhanot; 2013. 
Pathak G, Chalise M, Parajuli S, Banstola S, Thakur P, Chauhan H S. Practice on Water, Sanitation and Hygiene among Mothers of Under-5 Years Children in Urban Slum of Butwal Sub-Metropolitan City: 2015. Nepal International Journal of Health Sciences \& Research (www.ijhsr.org) 362 Vol.5; Issue: 12; December 2015

Pickering AJ, Djebbari H, Lopez C, Coulibaly M, Alzua ML. 2015. Effect of a community-led sanitation intervention on child diarrhoea and child growth in rural Mali: a clusterrandomised controlled trial. The Lancet Global Health 3, e701-e711.

Prüss-Ustün A, Bartram J, Clasen T, Colford JM, Cumming O, Curtis V, Bonjour S, Dangour AD, De France J, Fewtrell L. 2014. Burden of disease from inadequate water, sanitation and hygiene in low-and middle-income settings: a retrospective analysis of data from 145 countries. Tropical Medicine \& International Health 19, 894-905.

PrussUstun A, Bos R, Gore F, Bartram J. Geneva: World Health Organization; 2008. [Last accessed on 2013 Nov 2]. Safer water, better health: Costs, benefits and sustainability of interventions to protect and promote health.

Rah J, Cronin A, Badgaiyan B, et al. Household sanitation and personal hygiene practices are associated with child stunting in rural India: a cross-sectional analysis of surveys. BMJ Open. 2015;5:e 005180-e05180.

Rima, K. S. et al. Assessment of the Knowledge, Attitude and Practice Regarding Water, Sanitation and Hygiene among Mothers of Under-five Children in Rural Households of Saptari District, Nepal. American Journal of Public Health Research, 2017, Vol. 5, No. 5, 163-169.

Smith, L., Ruel, M. T., \& Ndiaye, A. 2005. Why is child malnutrition lower in urban than in rural areas? Evidence from 36 developing countries. World Development, 33(8), 12851305. https://doi.org/10.1016/j. worlddev. 2005.03.002

Sunny, A.R., Alam, R., Sadia, A.K., Miah, Y., Hossain, S., Mofiz, S.B., et al. 2020b. Factors affecting the Biodiversity and Human Well-Being of an Ecologically Sensitive Wetland of North Eastern Bangladesh. Journal of Coastal Zone Management, 23 (1):471,

Sunny, A.R., Masum,K.M.,Islam, N.,Rahman, M.,Rahman, A.,Islam, J.,Rahman,S., Ahmed, K.J., Prodhan, S.H. 2020a. Analyzing livelihood sustainability of climate vulnerable fishers: Insight from Bangladesh. Journal of Aquaculture Research and Development.11(6):593, doi: 10.35248/2155-9546.19.10.593 
Sunny, A.R., Prodhan, S.H., Ashrafuzzaman, Ahamed, G.S., Sazzad, S.A., Mithun, M.H., Haider, K.M.N., Alam, M.T. 2021b. Understanding Livelihood Characteristics and Vulnerabilities of Small-scale Fishers in Coastal Bangladesh. Journal of Aquaculture Research and Development.12(4):635

Sunny, A.R., Prodhan, S.H., Ashrafuzzaman, M., Mithun, M.H., Hussain, M., Alam, M.T., Rashid, A. and Hossain, M.M., 2021c. Fisheries in the context of attaining Sustainable Development Goals (SDGs) in Bangladesh: COVID-19 impacts and future prospects. Sustainability, 13 (17) 9912. https://doi.org/10.3390/su13179912

Sunny, A.R., Prodhan, S.H., Ashrafuzzaman, Sazzad, S.A., Rahman, M.A., Billah, M.M., Hussain, M., Rahman, M., Haider, K.M.N., Alam, M.T. 2021a. Livelihoods and vulnerabilities of small-scale fishers to the impacts of climate variability and change: insights from the coastal areas of Bangladesh. Egyptian Journal of Aquatic biology and Fisheries. 25 (4), pp. 549-571, doi:10.21608/ejabf.2021.191652,

UNICEF 2013. Improving child nutrition: The achievable imperative for global progress. New York: UNICEF.

UNICEF, WHO \& The World Bank 2012. Joint child malnutrition estimates: levels and trends. New York: UNICEF

UNICEF. 2009. Diarrhoea: why children are still dying and what can be done. www. unicef. org/media/files/Final_Diarrhoea_Report_October_2009_final.

UNICEF. 2015. Progress on Sanitation and Drinking Water-2015 Update and MDGs Assessment.

Van Minh H, NguyenViet H. Economic aspects of sanitation in developing countries. Environ Health Insights. 2011;5:63-70. [PMCID: PMC3212862] [PubMed: 22084575]

Water Aid Bangladesh, 2011, Water, Sanitation and Hygiene:[cited 2011 Apr 17].

WHO/UNICEF 2015. Water, sanitation and hygiene in health care facilities: status in low- and middle-income countries and way forward. Geneva: World Health Organization (http://who.int/water_sanitation_health/publications/wash-health-care-facilities/en/, accessed 7 September 2015).

Wright J, Gundry S, Conroy R. 2004. Household drinking water in developing countries: a systematic review of microbiological contamination between source and point-of-use. Trop Med Int Health. 9(1):106-17. 
